\title{
Risk Factors for the Involvement in Criminal Behaviors in Adolescence
}

\author{
Eglantina Dervishi
}

Artemisi Shehu

Department of Psychology and Pedagogy, Faculty of Social Sciences, University of Tirana,

Silva Ibrahimi

Departament of Psychology, Albanian University,

Ani Beqo

Blerta Doci

Departament of Social Issues, General Directorate of Prisons

Valbona Muca

Departament of Social Work,Faculty of Education "Aleksander Xhuvani" University of Elbasan, Tirana Albania

\begin{abstract}
The objective of this study is to present a general overview of the risk factors that are defined by the youth as causes for their involvement in criminal activities. Method: The sample of the present study consist of 78 youth who have been sentenced in the Albanian Executive Penitenciary Institutions, regarding data collected by the interviews that inestigate within family and peer relationships as well as statistics of the institutions where juvenile serve their sentence. Data refer to the 2014-2015 time extention. Results: The number of youth involved in criminal behaviors is considerable and referring to the statistics it is progressively increasing. As it seems some indicators related to the family environment are revealed as risk factors for the commitment of juveniles in criminal behavior. Despite the influence of the personal and family factors have in juvenile criminal behavior, the peer influence is another potential risk factor. Conclusions: Teeanage needs to be seen as a very delicate period where the external inflences strongly affect the way the adolescent will try to recognize and orient themselves in life. The powerful influence of familiar facotrs through his or her development will be introduced in the mode how the adolescent will posit themselves as an adult with responsibilities to his living environment. Influences of the familiar factors will affect in their turn the way the adolescents will choose to display himself in front of peers and will be influenced either by them in an effort to find themselves and their path in life.
\end{abstract}

Keywords: adolescent, family, criminal behavior, risk factor ,peers.

\section{Introduction}

Youth commitment into criminal actions is a known occurrence of the modern societies and of course our country which cannot be an exemption. The phenomenon of involving youth into criminal behaviors have wondered our society since the raising number recently.

In this context, it is of highly relevance to clear the age-boundaries of the minors involved in criminal activities with the purpose of evidencing and defining the targeted-group based in the Albanian legislation.

Specifically, referring to the legislation, "children"or "juvenile" is considered the person under the age of 18. Individuals under this age, are grouped in:

-Individuals under 14 years old 
-Individuals under 14-18 years old

According to the Penal Act of the Republic of Albania, the minimal limit to charge penal responsibilities is 14 years old. For the individuals at 14-18 years old, the penal law take use of the term "juvenile" (Hysi,2000). Studies completed in the field revealed that the delinquent behavior of the youth is generated by the psycho-social risk factors (Duggan, Jones, 2017) which interact between them. In an effort to analyze the causes of this quite disturbing phenomenon, it seems that the role of family and peers to have a significant influence relating to the criminal behaviors (Greenman, Matsuda, 2016). This paper aims to present the situation of the youth in law conflict, focusing essentially in the factors that constitute a risk for youth involvement into criminal behavior. In the context, the aimed target-group are the youth in law conflict at the Executive Penal Resolution Institutions. Studies in the field have revealed that juvenile criminal behavior is produced by the inapproriate parental practices (Kuhl et al., 2015) that constitute one of the causes and predictors most powerful of delinquency. In comparison to the children of families without behavioral issues, in the families with children who show these forms of matters, it is thought that they unintentionally reinforce the negative behavior of children. Children maltreatment or abuse, is generally associated with other family risk factors and in commiting delinquent acts in early ages (Bernasco et al., 2013). Focusing especially in the relationship between the physical abuse and aggressivity shown by the youth, a study in this context suggest that $20 \%$ of abused children turns in delinquents before the adult age. Being witness at family violence (Zweing et al., 2014) affects in the increase of behavioral problems especially in males. Also, according to studies in field it results that in many families where mothers are subject to violence, at the same time, children are subject to violence. Being abused or witness of family violence is thought to affect juvenile behavior twice more than being only a witness to violence (Kaplan et al., 2016).

Compared to males, whose parents remained married, males with divorced parents are thought to show more issues of the antisocial and not compliant behavior along the 10 years old. The results of a study conducted, about $45 \%$ of juvenile male parents with behavior problems (Henggeler et al., 1998); suffers of antisocial personality disorder (O'Connell et al., 2009). The same levels were reported for substance abuse and depression. It is widely thought that peers with deviant behavior have more influence on the youth with a criminal history regarding the increase of number and severity of criminal acts (Carpentier et al., 2011). Research in the field have shown data that reveal that criminal groups exert a considerable influence in the delinquent behavior of their members imposing the member's conformity to the group norms (Deslauriers et al., 2010). Recent studies reveal that refused teens from their peers are several times more riskiness to show an antisocial behavior (Freeman et al., 2005) in the same way in future compared to the non-refused children. Through interviews conducted it is aimed to explore on the risk factors that push youth to be involved in delinquent behavior.

\section{Methodology}

Research study are focused in the exploration of risk factors related to family dynamics and peers relationships. The sample of this research are juvenile who are sentenced in four Executive Penintenciary Institutions (I.E.V.P) in the Republic of Albania. This sample is composed of 78 youth who were sentenced for different offences. The time of data collection regards the years of 2014-2015. Youth in law conflict in the period of interview were all males. The instrument used in generating data analysis was a child's interview focusing in the exploration of their relationship and the possible family influence of peer as the adult perception. The length of the interview were 15 minutes where youth were assisted by a specialist of the social affairs department.

\section{Procedures}

Initially the relevant institutions were informed regarding the aim and the procedures of the research and we have taken the authorization for implementing. On the study aims we either informed the juveniles in legal conflicts, who accepted to be involved in the study. Ahead of the intervew, participants were given the neccessary explainations about the study purpose and confidentiality of identification data. Juveniles who voluntarily accepted to be contribute in the development of the study, were ensured with the confidentiality and anonymity of their responses.

\section{Results and discussions}

Juvenile involvement in criminal behavior referring to I.E.V.P. statistics in the period of 2015 concerning the court final decision judgement, reveals that only 20 adolescents have been sentenced whereas the other part are in the trial process (refer to table 1). 
Table 1. Number of minors in Penintenciary I.E.Acts, November 2015

\begin{tabular}{|l|l|l|}
\hline Institutions & Detainess & Convinced \\
\hline Kavajë & 20 & 20 \\
\hline Vlorë & 18 & \\
\hline Korça & 3 & \\
\hline Lezhë & 17 & \\
\hline
\end{tabular}

Referring to the objective of exploration of the risk factors in criminal behaviors concerning family and peers, it results that $8 \%$ of the youth have had a family member involved in criminal activity. This factor may negativily affect adolescents. Another component resulting by the interviews is that $15 \%$ of them report to have a family member sentenced with a final decision. In about $7 \%$ of the youth it is encountered an alcoholics abuse family member (relating to an alchoholic father). The lack of care throughout the growing process and especially in the early pre-adolescence time is claimed by $8 \%$ of the minors. Family did not express any interes for the feelings and issues the minor faced. Another concerning indicator relates to the irregular surveillance and parenting styles without defined boundaries which may push the teen into confussion regarding parental roles and in an increase levels of anxiety and stress as a lack of structuring and rules in the familiar context that the adolescent has in particular a need during this growing phase. In about of $8 \%$ minors report that in their familiar environment were often a subject of physical, sexual or emotional violence. Whereas $10 \%$ of them declare they were witness of family violence. About $10 \%$ of adolescents reveal experiencing the loss of a family member. In $13 \%$ of youth have had to take care and be responsible for another family member. $19 \%$ of them reveal that they had to face with other problems as some issues of mental health of parents, abandonment, divorce etc.

The second factor examined in the study was the presence of peers as risk factors in involvement of criminal behavior during adolescence. Referring to the data collected from interviews with youth was provided that: about $21 \%$ of the minors have not any social relationships with peers, and $43 \%$ of them consort with peers involved into criminal behavior, about $26 \%$ state they have not any socialization and link with criminal behaviors. Regarding to criminal acts it comes that $34 \%$ of adolescents have commited their offense in groups and that $43 \%$ of them realized that they had no one to pass their leisure time, thus a lack of suitable activities to develop a working routine for the young. The majority of minors $52 \%$ claims to pass their free time in streets or adult places, $24 \%$ declares they often have been involved into risk activities and lastlty $43 \%$ refer they have to provide themselves their income sources as neither their family helped them nor they had a work. Since this framework we could reveal that regarding family as risk factors we encounter a very interesting combination of factors that weigh the picture and seriously threat the normal development of adolescents. Refering our research that growing into an unstructured and iregular environment, not having the parental attention and care, the involvement of a family member in criminal activities, having a sentenced family member, growing in a physical, emotional and sexsual violent environment, facing an alcoholic parent, being witness of a family violence, being orphaned and having in charge family members develop a full picture of the risk factors concerning family. Regarding peer influence it seems that as risk factors in the involvement of adolescents in criminal behaviors a significance lays in the factors relating to the lack of relationships with peers, involvement and passing time with friends employed into criminal activities and not having friendship relations with non delinquent adolescents.

\section{Conclusions}

The more riskiness adolescents to be involved in criminal behavior during the period but also in a continuity of their life have a mix of factors that constitute a very serious view.

The strongest influence is seemed to be on the factors related with family dynamics. Anyway, the relation between a family who is not present and does guide adolescent to find their way, increase the chance in the influence of peers. It is important to supervise teens life not aiming to control them but to sustain and orient in this period of big physical-psychic-emotional changes. The role of family is decisive in the way we will try to keep youth away from crime. A very positive component is 
to design and implemet rehabiliation programs of youth in the penintenciary institutions. Eventhough, these programs would not bring stable changes in the improvement of youth behavior, if there is not reduction in the risk factors and if there are not structures that offer re-integration programs in post-release time.

\section{References}

[1] Bernasco, W., Bruinsma, G. J., Pauwels, L. J., \& Weerman, F. M. (2013). Adolescent delinquency and diversity in behavior settings. Australian \& New Zealand Journal of Criminology, 46, 357-378.

[2] Caplan, J. M., \& Kennedy, L. W. (2016). Risk Terrain Modeling: Crime prediction and risk reduction. Oakland: University of California Press.

[3] Carpentier, J., Leclerc, B., \& Proulx, J. (2011). Juvenile sexual offenders: Correlates on onset, variety and desistance of criminal behavior. Criminal Justice and Behavior, 38, 854-873.

[4] Deslauriers-Varin, N., \& Beauregard, E. (2010). Victims' routine activities and sex offenders' target selection scripts: A latent class analysis. Sexual Abuse: A Journal of Research and Treatment, 22, 315-342.

[5] Duggan. C, Jones. R, (2017). Managing uncertainty in the clinical prediction of risk of harm: Bringing a Bayesian approach to forensic mental health. Criminal Behaviour and Mental Health, Volume 27, Issue 1, 1-7.

[6] Freeman, K. A., Dexter-Mazza, E. T., \& Hoffman, K. C. (2005). Comparing personality characteristics of juvenile sex offenders and non-sex offending delinquent peers: A preliminary investigation. Sexual Abuse: A Journal of Research and Treatment, 17, 3-12.

[7] Greenman. S, Matsuda. M. (2016). From Early Dating Violence To Adult Intimate Partner Violence: Continuity And Sources Of Resilience In Adulthood. Criminal Behaviour and Mental Health, Special Issue: Dating Violence, Volume26, Issue4, 293-303.

[8] Henggeler, S. W., Schoenwald, S. K., Borduin, C. M., Rowland, M. D., \& Cunningham, P. B. (1998). Multisystemic treatment of antisocial behavior in children and adolescents. New York, NY: Guilford Press

[9] Hysi. V. (2000). Hyrje nw Kriminologji. Cikwl Leksionesh, 25-28.

[10] KUHL. C, WARNER. D, WARNER. T. (2015). Intimate Partner Violence Risk Among Victims Of Youth Violence: Are Early Unions Bad, Beneficial, Or Benign?. Criminology, Volume 53, Issue3, 427-456.

[11] O'Connell, M. E., Boat, T., \& Warner, K. E. (Eds.). (2009). Preventing mental, emotional, and behavioral disorders among young people: Progress and possibilities. Washington, DC: National Academies Press.

[12] Zweig. J, Yahner. J, Dank. M, Lachman.P (2014). Can Johnson's Typology Of Adult Partner Violence Apply To Teen Dating Violence?: Journal of Marriage and Family, volume 76, Issue 4, 808-825. 